\title{
A TUTELA JURÍDICA DA ÁGUA NO BRASIL: REFLEXÕES A PARTIR DOS DIREITOS DA NATUREZA
}

\author{
THE LEGAL PROTECTION OF WATER IN BRAZIL: MEDITATIONS ON \\ NATURE'S LAW
}

\begin{abstract}
Sérgio Ricardo Fernandes de Aquino
Doutor e Mestre em Ciência Jurídica pela Universidade do Vale do Itajaí - UNIVALI. Professor Permanente do Programa de Pós-Graduação Stricto Sensu - Mestrado - em Direito do Complexo de Ensino Superior Meridional - IMED. Professor do Curso de Direito da Faculdade Meridional - IMED. Pesquisador da Faculdade Meridional. Coordenador do Grupo de Pesquisa: Ética, Cidadania e Sustentabilidade. Membro do Grupo de Pesquisa: "Modernidade, Pós-Modernidade e Pensamento Complexo", "Multiculturalismo e Pluralismo Jurídico" e "Transnacionalismo e circulação de modelos jurídicos". Membro associado do Conselho Nacional de Pós-Graduação em Direito - CONPEDI e da Associação Brasileira do Ensino de Direito - ABEDI. E-mail: sergiorfaquino@gmail.com

Luanna Porto Rocha Cavalheiro Mestre em Direito, Democracia e Sustentabilidade pelo Programa de Pós-Graduação em Direito da Faculdade Meridional. E-mail: luanna.cavalheiro@hotmail.com

Mayara Pellenz

Mestre em Direito, Democracia e Sustentabilidade pela Faculdade Meridional - IMED.

E-mail: maypellenz@ hotmail.com

Recebido em: 16/03/2016

Aprovado em: 24/05/2016

Doi: $10.5585 / \mathrm{rdb} . v 14 \mathrm{i} 6.366$

RESUMO: A preservação da água não se exaure como simples objeto de manutenção à vida das presentes e futuras gerações. Os seus destinatários não podem ser apenas os seres humanos, mas a esses cabe a responsabilidade e a administração para que todos os seres vivos possam usufruir de seus benefícios. O objetivo geral deste estudo é analisar os limites da tutela jurídica da água no Brasil a partir da visão Sul-Americana, quando essa é considerada "sujeito" ao invés de "objeto". O método de abordagem utilizado será o dedutivo. Essa é a preocupação dos Direitos da Natureza que, se comparado à Legislação brasileira sobre Direito Ambiental, inova acerca da tutela jurídica da água para todos os seres.
\end{abstract}

Palavras-Chave: Água. Direito da Natureza. Legislação brasileira. Sujeito de Direito.

ABSTRACT: Water's preservaiton does not end as a mere object of maintaining the life of present and future generations. Its benefits reaches all and not only human beings, but people have the responsibility to manage this resource that all living beings can use it. The objective of this study is to analyze the limits of legal protection of water in Brazil in the South American vision, when this is considered "subject" rather than "object". The approach method is deductive. This is the concern of Nature's Rights that, compared to the Brazilian legislation on Environmental Law, innovates on the legal protection of water for all beings.

Keywords: Water. Nature's rights. Brazilian's law. Law's subject. 
SUMÁRIO: Introdução; 1. A água em terras brasileiras; 1.1. A água na Constituição Federal de 1988; 1.2. Aspectos infraconstitucionais da água; 2. Necessidade de uma nova postura em relação à água: a questão do redimensionamento; Conclusão; Referências.

\section{INTRODUÇÃO}

Atualmente, vive-se um período histórico peculiar em todo o processo civilizatório. É a primeira vez que, de uma forma bastante intensa, diversos setores sociais, saberes e autoridades científicas mobilizam-se a respeito da Natureza e a forma com que o Homem com ela se relaciona. Percebe-se como a consciência compartilhada, nesse sentido, é instrumentalizada pelo Direito. Esse, por ser um fenômeno cultural, é capaz de tutelar o mundo natural para que a crise ecológica seja contornada, diante das consequências oriundas do modelo de desenvolvimento vigente.

Dentre os temas mais debatidos, hoje, existe um no qual se sobressai aos demais: a importância da água. Esta, como indispensável a todas as formas de vida, precisa de uma atenção especial, diante de sua escassez. Os relatórios divulgados por organismos científicos sobre o tema são pessimistas, no tocante a sua quantidade e também a sua qualidade. Já existem lugares onde a água não é acessível a todos ou já se exauriu. Esse fator compromete todas as vidas as quais estão localizadas naquele território. Em outras palavras: a água não possui a qualidade necessária para ser consumida e essa condição provoca danos irreversíveis à qualidade da saúde.

Por outro lado, existe, ainda, um viés mercantilista, na qual a água adquire importância para indústrias, empresas, sistemas de irrigação e tantos outros exemplos que poderiam ser trazidos e que demonstram a necessidade da sua preservação para o desenvolvimento e para a manutenção de todas as formas de vida na Terra.

O ponto de partida dessa pesquisa é a necessidade de uma nova relação do Homem com a água. Diante de sua essencialidade, é preciso rever se os modelos de desenvolvimento adotados, inclusive pela legislação, oportunizam a distribuição de água e a sua sadia manutenção para que haja vida em abundância. Para tanto, novos comportamentos precisam ser adotados, em relação ao consumismo ${ }^{1}$, e novos valores precisam ser vivenciados para que a valorização deste elemento vital seja concretizada.

O Objetivo Geral desta pesquisa é analisar a tutela jurídica da água no Brasil e a necessidade de um redimensionamento de seu tratamento, especialmente se, a partir da visão SulAmericana, essa for considerada "sujeito" ao invés de "objeto". Neste viés, a Sustentabilidade também será abordada, à medida que sua dimensão ambiental diz respeito tanto à manutenção de todas as formas de vida, em uma perspectiva intergeracional, quanto à questão da crise da água.

Os Objetivos Específicos podem ser descritos nos seguintes tópicos: a) Definir o que é a água e sua importância para a manutenção das vidas e ecossistemas; b) identificar a função social da legislação brasileira acerca da preservação de água; c) reconhecer a água não apenas como objeto de exploração humana, mas como "ser próprio" segundo aquilo que preconiza a visão sulamericana.

O método de abordagem utilizado para esta pesquisa é o Dedutivo ${ }^{2}$, cuja premissa maior é a existência da legislação acerca da proteção da água e, como premissa menor, tem-se a sua

\footnotetext{
${ }^{1}$ Segundo Bauman (2008, p. 43), consumismo corresponde "[...] não tanto à satisfação de necessidades (como suas "versões oficiais" tendem a deixar implícito), mas a um volume e uma intensidade de desejos sempre crescentes, o que por sua vez implica o uso imediato e a rápida substituição dos objetos destinados a satisfazê-la. Novas necessidades exigem novas mercadorias, que por sua vez exigem novas necessidades e desejos; o advento do consumismo inaugura uma era de "obsolescência embutida" dos bens oferecidos no mercado [...]".

2 “[...] base lógica da dinâmica da Pesquisa Científica que consiste em estabelecer uma formulação geral e, em seguida, buscar as partes do fenômeno de modo a sustentar a formulação geral”. (PASOLD, 2011, p. 205).
}

Revista de Direito Brasileira | São Paulo, SP | v. 14 | n. 6 | p. 65 - 79 | maio/ago. 2016 
utilização e (in)eficácia para a preservação da vida. As técnicas eleitas para cumprir o caminho cognitivo mencionado são a Pesquisa Bibliográfica ${ }^{3}$, a Categoria $^{4}$ e o Conceito Operacional ${ }^{5}$.

\section{A ÁGUA EM TERRAS BRASILEIRAS}

Observa-se que o Brasil é um país abundante no que se refere ao Meio Ambiente, diante da diversidade natural aqui encontrada. Existem diversos elementos que enriquecem o país, no tocante à fauna, à flora, às espécies de animais e de plantas, dentre outros. Esse cenário é enriquecido pela água, pois o Brasil detém $12 \%$ da água doce existente no mundo.

No entanto, a distribuição desse elemento não é igualitária, por uma questão geográfica e natural, a qual, no Norte, a água é encontrada em maior quantidade e, no Sul, em quantidades menores. Essa desproporção não é exclusiva do espaço geográfico brasileiro, mas provocou, recentemente, um problema gravíssimo de abastecimento no Estado de São Paulo em que os níveis dos reservatórios marcaram recordes de esvaziamento. Esse cenário lembra, de modo significativo, o cenário o qual ocorreu no ano 2000 na cidade de Cochabamba na Bolívia pela má administração do uso das águas.

Esse fato chamou atenção da comunidade nacional e internacional, desvelando que o tema possui uma dimensão global. Segundo Carli (2013, p. 145) a utilização desordenada e a poluição das águas, têm sido uma das maiores preocupações transfonteiriças. Isso demonstra a necessidade de uma reflexão mais detalhada a respeito da proteção da água, essencial à preservação da vida no Planeta. Entretanto, a legislação brasileira, constitucional e infraconstitucional, adota o antropocentrismo alargado ${ }^{6}$ no tratamento da água, ou seja, a matriz de significalidade ainda é o humano em detrimentos aos outros seres vivos.

$\mathrm{Na}$ legislação brasileira, não há artigo expresso que eleve a água à Direito Fundamental ${ }^{7}$. Entende-se a água como Direito Fundamental no Brasil por meio dos princípios ambientais, das resoluções, tratados e convenções das Organizações das Nações Unidas, ou seja, no Brasil, essa está no mesmo patamar dos outros direitos ambientais. Na retomada histórica das Constituições

\footnotetext{
3 “[...] Técnica de investigação em livros, repertórios jurisprudenciais e coletâneas legais”. (PASOLD, 2011, p. 207).

${ }^{4}$ Nas palavras de Pasold (2011, p. 25): “[...] palavra ou expressão estratégica à elaboração e/ou expressão de uma idéia”. Grifos originais da obra em estudo.

${ }^{5}$ Reitera-se conforme Pasold (2011, p. 37): “[...] uma definição para uma palavra ou expressão, com o desejo de que tal definição seja aceita para os efeitos das ideias que expomos [...]". Grifos originais da obra em estudo.

6 "Nota-se, assim, que a Constituição brasileira não deixa de adotar o antropocentrismo no que concerne ao ambiente. Entretanto, o antropocentrismo é alargado, não se restringindo o ambiente a mera concepção econômica ou de subalternidade direta a interesses humanos. Observa-se, plenamente, contudo, que a autonomia do ambiente, alçada no texto constitucional, é bastante diversa daquela propugnada pela ecologia profunda". (LEITE, 2012, p. 167)

${ }^{7} \mathrm{Na}$ Constituição da Bolívia a água constitui-se direito fundamental à vida e é um marco caracterizador da soberania do povo, no Título II - Capítulo V, o artigo $16^{7}$ - I traz a água como direito fundamental expresso. Visando elevar a água a direito fundamental expresso constitucionalmente, e também como uma das soluções da Guerra del Agua, a Bolívia positivou alguns artigos em sua constituição que deram maior enfoque a proteção da água. $\mathrm{O}$ artigo 20 , que fica inserido no Título II, trata dos direitos fundamentais e, prescreve que toda persona tiene derecho al acceso universal y equitativa a los servicios básicos de agua potable, alcantarillado, electricidad, gas domiciliario, telecomunicaciones y transporte, neste sentido todas as pessoas têm direito a água potável, e o mesmo artigo afasta a privatização da água potável no inciso III los servicios básicos no serán objeto de concesión ni privatización. Na visão da Constituição boliviana eleva-se o direito à água Direito Humano Fundamental, indissociável do direito à vida e dos demais Direitos Humanos Fundamentais. Emancipa o direito à água da concepção econômica, como instrumento de produção e, a considera patrimônio comum, proibindo a sua privatização. Na concepção desses novos direitos, este pensamento de priorização de interesses unicamente humanos é que precisa se modificar, ou seja, devese sustentar uma visão de um desenvolvimento que prima pela proteção da natureza. Com isso, a relação entre homem e natureza se redimensiona.
}

Revista de Direito Brasileira | São Paulo, SP | v. 14 | n. 6 | p. 65 - 79 | maio/ago. 2016 
Federais anteriores a de 1988, verifica-se algumas situações que merecem destaque nessa pesquisa.

A Constituição Imperial de 1824, por exemplo, não fez menção ao meio ambiente, principalmente quanto a água. No entanto, a Lei de $1^{\circ}$ de outubro de 1828 disciplinou que as Câmaras Municipais tivessem a competência para legislar sobre: aquedutos, chafarizes, poços, tanques, bem como esgotamento de pântanos e qualquer estagnação de água. O Ato Adicional Lei $\mathrm{n}^{\circ}$ 16, de 12 de agosto de 1834, estabelece que as Assembleias Legislativas provinciais legislassem sobre obras públicas, estradas e navegação no interior.

No período republicano, tem-se a Constituição de 1891, a qual também foi omissa quanto às regras sobre o uso da água. Essa norma jurídica limitou-se a legislar sobre a competência federal para legislar sobre Direito Civil, e este, o Código Civil de 1916, trouxe vários artigos sobre o uso da água.

A preocupação no início do Século XX era com o capital, espírito esse constatado na Constituição de 1934. Essa foi a primeira a legislar sobre a água, tratada em alguns artigos como bem da União. A água foi tratada como bem de uso para a geração de riquezas, especialmente como fonte de energia elétrica (ANTUNES, 2009, p. 76). A Constituição Federal de 1937 no seu artigo 143 instituiu que:

As minas e demais riquezas do subsolo, bem como as quedas d'água constituem propriedade distinta da propriedade do solo para o efeito de exploração ou aproveitamento industrial. $\mathrm{O}$ aproveitamento industrial das minas e das jazidas minerais, das águas e da energia hidráulica, ainda que de propriedade privada, depende de autorização federal. $\S 1^{\circ}$ - A autorização só poderá ser concedida a brasileiros, ou empresas constituídas por acionistas brasileiros, reservada ao proprietário preferência na exploração, ou participação nos lucros; $\S 2^{\circ}-\mathrm{O}$ aproveitamento de energia hidráulica de potência reduzida e para uso exclusivo do proprietário independe de autorização; $\S 3^{\circ}$ - Satisfeitas as condições estabelecidas em lei entre elas a de possuírem os necessários serviços técnicos e administrativos, os Estados passarão a exercer dentro dos respectivos territórios, a atribuição constante deste artigo; $\S 4^{\circ}$ - Independe de autorização o aproveitamento das quedas d'água já utilizadas industrialmente na data desta Constituição, assim como, nas mesmas condições, a exploração das minas em lavra, ainda que transitoriamente suspensa.

A redação desse artigo demonstra uma postura essencialmente antropocêntrica, pois o tratamento da água, nessa determinação constitucional relaciona-se com o aproveitamento industrial da água. Não havia qualquer apreço sobre a importância vital da água fora de um exclusivo juízo de valor puramente econômico ${ }^{8}$.

Antunes (2009, p. 88) esclarece que as Constituições de 1967 e 1969 mantiveram a água como bem da União, ou seja, os lagos e quaisquer correntes de água em terrenos de seu domínio, ou que banhem mais de um Estado, constituam limite com outros países, ou se estendam a territórios estrangeiros, e as ilhas oceânicas, assim como as ilhas fluviais e lacustres nas zonas limítrofes com outros países. Quanto à competência legislativa federal, foi afastada a supletiva e mantida a competência exclusiva da União para legislar sobre água.

Percebe-se que as Constituições brasileiras possuíam abordagens discretas em ralação a água. Mantiveram em pauta a normatização quanto ao uso desta para industriais, revelando o

\footnotetext{
${ }^{8}$ Esta diversidad hace posible dar un paso más para reconocer valores que son propios de la Naturaleza. Estos son intrínsecos o inherentes a los seres vivos y sus ambientes, y por lo tanto son independientes de las valoraciones que se hacen basadas en la utilidad comercial de los recursos narturales. (GUDYNAS, 2014, p. 45)
}

Revista de Direito Brasileira | São Paulo, SP | v. 14 | n. 6 | p. 65 - 79 | maio/ago. 2016 
caráter antropocêntrico com relação a água. Com a Constituição Federal de 1988, a preservação à água ganhou um novo enfoque, especialmente no tocante ao domínio público das águas.

\subsection{A ÁGUA NA CONSTITUIÇÃO FEDERAL DE 1988}

A Constituição de 1988 prescreve que a água é bem de domínio público. Em relação aos recursos hídricos, outorga-se à União e aos Estados o seu domínio, não há mais a figura das águas particulares (CARLI, 2013, p. 143). As normas constitucionais conferem maior enfoque quanto à proteção constitucional das águas. A Constituição Federal previu o fim da privatização do uso água, já que se trata de um bem comum ${ }^{9}$.

É a partir dessa estratégia na qual a gestão integrada dos recursos hídricos se torna acessível a todos. A água, para ser utilizada, exige pagamento de um preço para impedir que toda a sociedade arque com os custos e benefícios (ANTUNES, 2009). Percebe-se que se abordou o tema com maior amplitude do que as Constituições anteriores, embora a perspectiva antropocêntrica ainda esteja presente.

A água é domínio da União. Segundo Antunes (2009, p.144), lagos, rios e quaisquer correntes de água em terrenos de outros países, que se estendam a território estrangeiro ou dele provenham, bem como os terrenos marginais e as praias fluviais, são bens da União. Disciplinou as ilhas fluviais e lacustres, a plataforma continental, o mar territorial e os potenciais de energia hidráulica no art. 20, incisos IV,V,VI,VII, VIII, da Constituição Federal ${ }^{10}$. Também no art. $176^{11}$

\footnotetext{
${ }^{9}$ Para Mattei (2013, p. 16/17): “[...] O tema dos bens comuns, de fato, tem a ver com a questão fundamental sobre o domínio das coisas e da relação da pessoa com a natureza. Por esse motivo, o tema não pode ser abordado, nem compreendido, sem expor no cerne do debate a dimensão institucional do poder e a sua legitimidade. [...] Pensar sobre os bens comuns exige, antes de tudo, uma postura central tipicamente global capaz de situar no centro do problema o problema do acesso igualitário das possibilidades que o planeta nos oferece. Uma perspectiva desse sentido suscita perguntas difíceis de contestar para quem opera numa fé inabalável sobre a constante depredação dos recursos naturais [...]". Tradução livre do original em espanhol dos autores deste texto.

${ }^{10}$ Art. 20. São bens da União:

I - os que atualmente lhe pertencem e os que lhe vierem a ser atribuídos;

II - as terras devolutas indispensáveis à defesa das fronteiras, das fortificações e construções militares, das vias federais de comunicação e à preservação ambiental, definidas em lei;

III - os lagos, rios e quaisquer correntes de água em terrenos de seu domínio, ou que banhem mais de um Estado, sirvam de limites com outros países, ou se estendam a território estrangeiro ou dele provenham, bem como os terrenos marginais e as praias fluviais;

IV - as ilhas fluviais e lacustres nas zonas limítrofes com outros países; as praias marítimas; as ilhas oceânicas e as costeiras, excluídas, destas, as áreas referidas no art. 26, II;

IV as ilhas fluviais e lacustres nas zonas limítrofes com outros países; as praias marítimas; as ilhas oceânicas e as costeiras, excluídas, destas, as que contenham a sede de Municípios, exceto aquelas áreas afetadas ao serviço público e a unidade ambiental federal, e as referidas no art. 26, II;(Redação dada pela Emenda Constitucional n 46, de 2005)

$\mathrm{V}$ - os recursos naturais da plataforma continental e da zona econômica exclusiva;

VI - o mar territorial;

VII - os terrenos de marinha e seus acrescidos;

VIII - os potenciais de energia hidráulica;

IX - os recursos minerais, inclusive os do subsolo;

$\mathrm{X}$ - as cavidades naturais subterrâneas e os sítios arqueológicos e pré-históricos;

$\mathrm{XI}$ - as terras tradicionalmente ocupadas pelos índios.

$\S 1^{\circ}$ É assegurada, nos termos da lei, aos Estados, ao Distrito Federal e aos Municípios, bem como a órgãos da administração direta da União, participação no resultado da exploração de petróleo ou gás natural, de recursos hídricos para fins de geração de energia elétrica e de outros recursos minerais no respectivo território, plataforma continental, mar territorial ou zona econômica exclusiva, ou compensação financeira por essa exploração.

$\S 2^{\circ}$ A faixa de até cento e cinqüenta quilômetros de largura, ao longo das fronteiras terrestres, designada como faixa de fronteira, é considerada fundamental para defesa do território nacional, e sua ocupação e utilização serão reguladas em lei. (grifo nosso)
}

Revista de Direito Brasileira | São Paulo, SP | v. 14 | n. 6 | p. 65 - 79 | maio/ago. 2016 
da Constituição Federal, quando trata dos princípios gerais da atividade econômica, traz que os potenciais de energia hidráulica constituem propriedade distinta da do solo para efeito de exploração ou aproveitamento.

Explica Antunes que no artigo $26^{12}$, inciso I, II, e III, da Constituição Federal de 1988, os bens pertencentes aos estados são as águas superficiais e subterrâneas, fluentes e emergentes, também as em depósito, ressalvadas, nesse caso, na forma da lei, as decorrentes de obras da União. Para Carli (2013, p. 144):

[...] entende-se que a Constituição Federal de 1988, nos artigos 20 e 26, quando inclui na relação de bens pertencentes à União e aos Estados, os mananciais de águas, não lhes atribui a propriedade dos recursos hídricos, mas tão somente lhes confere o dever de gestão dessa riqueza que, na verdade, pertence à coletividade brasileira e aos demais seres vivos.

Nesse viés, a União detém a competência privativa para legislar sobre águas, mas cabe em comum à União, aos Estados, ao Distrito Federal e aos Municípios a defesa do meio ambiente e o combate à poluição. Assim, todos os entes podem legislar sobre águas desde que seja para combater a poluição e proteger o meio ambiente. Cabe ressaltar que, a despeito do novo paradigma da Sustentabilidade, também se aplica à água o caput do artigo 225 da Constituição Federal de 1988:

Art. 225 Todos têm direito ao meio ambiente ecologicamente equilibrado, bem de uso comum do povo e essencial à sadia qualidade de vida, impondo-se ao Poder Público e à coletividade o dever de defendê-lo e preservá-lo para as presentes e futuras gerações.

Neste artigo, fica evidenciado que as águas passaram a ter uma proteção especial, para garantir à presente e as futuras gerações um meio ambiente equilibrado. Na Constituição Federal de 1988, em comparação com as Constituições anteriores, a água adquiriu uma importância considerável. Contudo, a despeito do antropocentrismo vigente, é evidente a necessidade de

\footnotetext{
${ }^{11}$ Art. 176. As jazidas, em lavra ou não, e demais recursos minerais e os potenciais de energia hidráulica constituem propriedade distinta da do solo, para efeito de exploração ou aproveitamento, e pertencem à União, garantida ao concessionário a propriedade do produto da lavra.

$\S 1^{\circ}$ A pesquisa e a lavra de recursos minerais e o aproveitamento dos potenciais a que se refere o "caput" deste artigo somente poderão ser efetuados mediante autorização ou concessão da União, no interesse nacional, por brasileiros ou empresa constituída sob as leis brasileiras e que tenha sua sede e administração no País, na forma da lei, que estabelecerá as condições específicas quando essas atividades se desenvolverem em faixa de fronteira ou terras indígenas. (Redação dada pela Emenda Constitucional nº 6, de 1995)

$\S 2^{\circ}$ É assegurada participação ao proprietário do solo nos resultados da lavra, na forma e no valor que dispuser a lei. $\S 3^{\circ}$ A autorização de pesquisa será sempre por prazo determinado, e as autorizações e concessões previstas neste artigo não poderão ser cedidas ou transferidas, total ou parcialmente, sem prévia anuência do poder concedente.

$\S 4^{\circ}$ Não dependerá de autorização ou concessão o aproveitamento do potencial de energia renovável de capacidade reduzida. (grifo nosso)

${ }^{12}$ Art. 26. Incluem-se entre os bens dos Estados:

I - as águas superficiais ou subterrâneas, fluentes, emergentes e em depósito, ressalvadas, neste caso, na forma da lei, as decorrentes de obras da União;

II - as áreas, nas ilhas oceânicas e costeiras, que estiverem no seu domínio, excluídas aquelas sob domínio da União, Municípios ou terceiros;

III - as ilhas fluviais e lacustres não pertencentes à União;

IV - as terras devolutas não compreendidas entre as da União.
} 
artigos específicos para regular a preservação da água, vez que, diante destes, comportamentos humanos serão redimensionados, diante do regulamento constitucional e sua exigibilidade.

Chama-se atenção ao fato de que, ainda que a agua não possua uma proteção legal tão completa e efetiva, são os atores sociais os responsáveis pela realização de tal direito, para que este não se mostre como (mais um!) dos projetos inalcançados pela Constituição Federal.

\subsection{ASPECTOS INFRACONSTITUCIONAIS DA ÁGUA}

Ao lado das normas constitucionais, é preciso destacar as leis infraconstitucionais de proteção às águas, que vigoram total ou parcialmente, e datam da primeira metade do Século XX. Dentre elas, cabe citar as mais importantes: Código de Águas (Decreto n. 24.643, de 10-7-1934), a Lei Federal n. ${ }^{\circ} 9.433$ (instituiu a Política Nacional de Recursos Hídricos), a Lei Federal n. ${ }^{\circ}$ 9.984 (criou Agência Nacional de Águas - ANA) e o Decreto Federal n. 3.692 (que complementa a estrutura operacional da ANA).

Justamente com este aparato jurídico, o Conselho Nacional do Meio Ambientedisciplina o uso, a outorga, a manutenção da qualidade e quantidade dos mananciais de água superficiais ou subterrâneas. Por exemplo: as resoluções n. ${ }^{\circ}$ 357/2005 e a n. ${ }^{\circ}$ 396/2008 do citado órgão tratam da qualidade, da quantidade e da manutenção da água em terras brasileiras.

Já a Lei Federal n. ${ }^{\circ}$ 9.605/1998 tipifica os crimes ambientais, entre eles o crime de poluição. Na esfera administrativa, o Decreto Federal n. ${ }^{\circ} 3179 / 99$ prevê as sanções administrativas para quem provocar ou causar poluição hídrica. A mais recente codificação sobre as águas está no Código Civil Brasileiro que entrou em vigor no ano de 2002.

Ressalte-se que o Código de Águas foi instituído pelo Decreto Federal n. ${ }^{\circ}$ 24.643/34 para disciplinar o aproveitamento e a preservação dos corpos d'água, desvelando a preocupação da sociedade brasileira com a manutenção da qualidade da água. Carli (2013, p. 143) explica que:

Os mananciais hídricos começaram a alcançar relevo no sistema normativo brasileiro, a partir do denominado Código de Águas, instituído pelo Decreto 24.643/34 de 10 de julho de 1934, que objetivou proteger as águas de qualquer evento danoso e poluidor. $\mathrm{O}$ diploma normativo em tela classificou as águas em: águas públicas (de uso comum e dominiais), águas comuns e águas particulares. Tal classificação, entretanto, recebe, hodiernamente, severas críticas, em especial, no tocante à espécie classificatória de águas particulares.

Embora o Código de Águas já tenha sido parcialmente revogado, chama-se atenção para o seu artigo $8^{\circ}$ o qual trazia a seguinte redação:

[...] São particulares as nascentes e todas as águas situadas em terrenos que também o sejam, quando as mesmas não estiverem classificadas entre as águas comuns de todos, as águas públicas ou as águas comuns.

Esse dispositivo não existe mais na esfera jurídica, pois contraria o enunciado do artigo 57 da Lei Federal no 9.433/97 e o disposto na Constituição Federal de 1988. Esses últimos dispõem que as águas são bens de domínio público, ou seja, na época em que foi editado o Código de Águas, as águas situadas nas nascentes, terrenos eram de propriedade dos donos da propriedade onde estas eram localizadas. Revogou-se, ainda, os artigos 68 a 95 do Código de Águas, os quais tratam sobre o aproveitamento das águas comuns e particulares, por serem públicas todas as águas (MILARÉ, 2007). Quanto ao aproveitamento das águas: 
O Código de Água trata no art. 34 e seguintes sobre o aproveitamento das águas, dispõe sobre águas comuns de todos, assegurando o uso gratuito de qualquer corrente ou nascente de água para as primeiras necessidades da vida, uso garantido independentemente do domínio das águas, possibilitando em áreas rurais o trânsito em terrenos particulares para acessar esta água (MILARÉ, 2007, p.467).

Quanto à gestão das águas, a preocupação era com a o uso de sua quantidade. Não trazia o Código de Águas nenhuma referência acerca da necessidade de tratamento ao uso da água potável. O objetivo central era o aproveitamento para hidroelétricas, tanto pela União quanto pelos Estados. Nesse ponto, destaca-se que:

O Código de Águas tratava das "águas nocivas" em seus art.109 a 116. Proibiam a qualquer pessoa "conspurcar ou contaminar as águas que não consome, com prejuízo de terceiros". Mas ás águas podiam ser "inquinadas" para salvaguardar interesse da agricultura ou indústria, mediante autorização administrativa, mediante indenização de terceiros lesados pelo favor concedido (MILARÉ, 2007, p.468).

A Lei Federal $n^{\circ}$ 9.433/97 determinou a proteção dos recursos hídricos e seu gerenciamento no uso e aproveitamento da água, além de alterar diversos dispositivos do Código de Águas. Partindo do princípio que a água doce é finita, de valor econômico e bem de uso comum, essa lei revogou artigos do Código de Águas datado de 1934 e estabeleceu novas regras para disciplinar o uso, a preservação e a manutenção das águas no planeta. Nessa linha de pensamento, Carlis (2013, p. 208) rememora:

A Lei 9.433/97 estabelece, entre os instrumentos da Política Nacional de Recursos Hídricos, a outorga dos direitos de uso de recursos hídricos e a cobrança pelo uso dessa riqueza natural, nos termos do artigo $5^{\circ}$. Reconhece-se nesses mecanismos quádrupla natureza, pois são, ao mesmo tempo, instrumentos de caráter político, jurídico, econômico e educativo. Na verdade, a outorga do uso da água, bem como a sua cobrança têm a função social de garantir o uso racional e sustentável do ouro azul, mas também de despertar o usuário acerca de seu papel de protetor dos mananciais de águas [...].

Essa Lei está vinculada à gestão do meio ambiente, pois aumenta a responsabilidade das políticas nacionais, sobre a importância da dimensão ecológica na preservação de todas as vidas a partir do uso responsável da água. Para Carli (2013, p. 213):

O referido diploma normativo tem como escopo dar concretude ao disposto no artigo 225 da Carta Maior de 1988, que estabelece como dever de todos a preservação do Meio Ambiente, e determina ao Poder Público a obrigação de implementar políticas públicas, no sentido de gerir e proteger o macrossistema ecológico, do qual as águas fazem parte.

Esse enunciado normativo executou o que está previsto na Constituição Federal de 1988 em seu artigo 21, XIX, o qual atribuiu à União a incumbência de instituir o Sistema Nacional de Gerenciamento de Recursos Hídricos e definir critérios de outorga de direitos de seu uso. O artigo 19 da citada lei demonstra a finalidade de cobrança pelo uso da água a partir dos fundamentos sócio-jurídicos expresso pela outorga do uso da água. 
A cobrança pelo uso de recursos hídricos objetiva: I - reconhecer a água como bem econômico e dar ao usuário uma indicação de seu real valor; II - incentivar a racionalização do uso da água; III - obter recursos financeiros para o financiamento dos programas e intervenções contemplados nos planos de recursos hídricos.

Chama-se atenção ao inciso II, que trata do incentivo à sua racionalização. $\mathrm{O}$ primeiro inciso é corolário do segundo e, o terceiro é considerado importante sob a perspectiva funcional, visto que os projetos e programas voltados a preservação das águas dependem de recursos. Dentre os objetivos da Lei $9.433 / 97^{13}$, destaca-se a necessidade de:

(i) assegurar à atual e às futuras gerações a necessária disponibilidade de água com qualidade adequada para seu uso; (ii) o uso racional e integrado dos recursos hídricos, com vistas ao desenvolvimento sustentável; (iii) a prevenção e a defesa contra eventos hidrológicos críticos, quer sejam de origem natural, quer decorram do uso inadequado, não só da água, mas também dos demais recursos naturais (MILARÉ, 2007, p.475).

Conforme o mesmo autor, os princípios básicos, a teor da Lei Federal n 9.433/97, são: 1) a água é bem de domínio público; 2) a água é um recurso natural limitado, dotado de valor econômico, as águas interiores, superficiais e subterrâneas constituem em um recurso natural finito e vulnerável, que, em período de escassez, o uso prioritário dos recursos hídricos é o consumo humano e a dessedentação de animais; 3) a gestão dos recursos hídricos deve sempre proporcionar o uso múltiplo das águas; 4) a bacia hidrográfica é a unidade territorial para implantação da Política Nacional de Recursos Hídricos e atuação do Sistema Nacional de Gerenciamento de Recursos Hídricos; 5) a gestão dos recursos hídricos deve ser descentralizada e contar com a participação do poder público, dos usuários e das comunidades.

O Código Civil, no Capítulo III, "Dos Bens Públicos e Particulares" prescreve no art. $99^{14}$ que os bens públicos: são de uso comum do Povo, tais como rios, mares, estradas ruas e praças.

Preconiza o Código Civil que os rios e os mares são bens de uso comum, embora, conforme a localização, há rios que estão sob os cuidados da União, e outros sob os cuidados e fiscalização dos Estados. Quanto à distribuição e lançamento de águas entre vizinhos, o Código Civil traçou normas visando evitar atritos entre as pessoas e principalmente para garantir o abastecimento para fins de garantir o atendimento indispensável às primeiras necessidades da vida.

\footnotetext{
${ }^{13}$ Art. $2^{\circ}$ São objetivos da Política Nacional de Recursos Hídricos:

I - assegurar à atual e às futuras gerações a necessária disponibilidade de água, em padrões de qualidade adequados aos respectivos usos;

II - a utilização racional e integrada dos recursos hídricos, incluindo o transporte aquaviário, com vistas ao desenvolvimento sustentável;

III - a prevenção e a defesa contra eventos hidrológicos críticos de origem natural ou decorrentes do uso inadequado dos recursos naturais. (LEI No 9.433, DE 8 DE JANEIRO DE 1997. Disponível em: http://www.planalto.gov.br/ccivil_03/leis/L9433.htm. Acesso em 25 de janeiro de 2016)

${ }^{14}$ Art. 99. São bens públicos:

I - os de uso comum do povo, tais como rios, mares, estradas, ruas e praças;

II - os de uso especial, tais como edifícios ou terrenos destinados a serviço ou estabelecimento da administração federal, estadual, territorial ou municipal, inclusive os de suas autarquias;

III - os dominicais, que constituem o patrimônio das pessoas jurídicas de direito público, como objeto de direito pessoal, ou real, de cada uma dessas entidades.

Parágrafo único. Não dispondo a lei em contrário, consideram-se dominicais os bens pertencentes às pessoas jurídicas de direito público a que se tenha dado estrutura de direito privado.
}

Revista de Direito Brasileira | São Paulo, SP | v. 14 | n. 6 | p. 65 - 79 | maio/ago. 2016 
Ao tratar o direito de vizinhança, o Código Civil dedicou a seção V para fixar normas sobre as águas e normatizar a relação dos proprietários de terrenos ou de áreas rurais e o tratamento das águas. Institui o Código que o fornecimento de água para as necessidades básicas obriga os proprietários a respeitar o curso natural das águas e o fornecimento de água de quem possui para aqueles que na sua propriedade não dispõe de água, entre outras obrigações, determinadas para prédios vizinhos ou contínuos. Desse modo:

Destarte, ao continuar a tratar a água, em pleno século XXI, como simples tema adaptado ao "direito de vizinhança", vinculado ao direito de propriedade, desconsidera o novo Código Civil a realidade brasileira: uma realidade marcada pela necessidade de acomodar quase 170.000 .000 de seres humanos, com a existência de mais de um milhão de pessoas em algumas capitais do País dentro de estruturas em que grande parte das moradias se encontram em "bairros espontâneos", que estão a necessitar não só de "aquedutos" mas de uma completa e bem estruturada organização visando adequar a pessoa humana ao meio ambiente artificial (FIORILLO, 2005, p.144).

O Código Civil Brasileiro de 2002, definiu a posição das águas, para recuperar e preservar os mananciais e previu algumas soluções para os conflitos surgidos entre os vizinhos. Muito embora, esta seja a mais recente codificação sobre a água e, ateou-se apenas aos direitos de vizinhança e a posição das águas, dado a amplitude da problemática da água vivida neste século, precisa-se de melhores argumentos sobre a preservação da água e solução para conflitos originários do direito civil e do direito da vizinhança.

\section{NECESSIDADE DE UMA NOVA POSTURA EM RELAÇÃO A ÀGUA: A QUESTÃo DO REDIMENSIONAMENTO}

Diante da crise ambiental instaurada no Planeta, nota-se que o Brasil é país atento à questão da água. Por certo, a proteção jurídica das águas em terras brasileiras não é suficiente, mas é preciso destacar que caminha de forma a evoluir nessa temática, especialmente a partir da Constituição Federal de 1988. Pensar a importância da água é visualizar, reconhecer o mosaico da vida, fragmentada na pluralidade de ecossistemas, os quais constituem verdadeira tessitura planetária nessa rede de sistemas vivos.

Mesmo que a legislação pátria contemple diversos aspectos sobre o elemento água, destaca-se, nesse ponto da pesquisa, a importância das ações humanas para a superação da crise instaurada. A construção de um olhar e agir fraternos e solidários, com respeito às diretrizes constitucionais a os direitos fundamentais previstos, são esforços que somam na busca da superação de concepções individualistas e antropocêntricas, as quais visem a reconstrução da relação entre Homem e Natureza ${ }^{15}$.

\footnotetext{
15 "Com o citado salto do ambientalismo para a ecologia profunda, emerge uma nova teoria do constitucionalismo latino americano, de modo particular, nos Andes, onde se opera uma a pré-falada revolução paradigmática do Direito -o giro ecocêntrico, com a institucionalização da cultura do Bem Viver, elevado a direitos fundamentais e a princípio constitucional, respectivamente, nas recentes reformas da Constituição do Equador em 2008, e da Bolívia em 2009, e eleito como eixo dos programas e planos de governo destes países. Detecta-se uma forte tendência biocêntrica, com a prevalência da cultura da vida. Para além deste forte acento biocêntrico, contudo, evidencia-se a positivação, sob a forma de diversos princípios, nos textos normativos, a indissociável relação de interdependência e complementariedade entre os seres vivos, o que leva a qualificá-lo mais adequadamente de constitucionalismo ecocêntrico". (MORAES, 2012, p. 13)
}

Revista de Direito Brasileira | São Paulo, SP | v. 14 | n. 6 | p. 65 - 79 | maio/ago. 2016 
Nessa tarefa, a Sustentabilidade ${ }^{16}$ envolve a concepção de vida e sua fragilidade, tal e qual a água. Sem água, não há vida. Sem Natureza, não há vida. É na relação entre vida (humana e não humana) e Planeta Terra que a Sustentabilidade está presente. Na realização humana e seu desejo de desenvolvimento social é que a fragilidade dos elementos que compõem o universo deve ser considerada.

A vulnerabilidade desses elementos deve fomentar uma nova consciência humana, qual seja, a de que o processo civilizatório deve estar pautado por precauções para a preservação do mundo natural, e, de forma especial, da água. Nesse ponto, Moraes (2013, p. 148) destaca que:

Nada obstante, entrevê-se uma contradição ao considerar que água seja ao mesmo tempo um ser vivo componente da natureza e convencioná-la como patrimônio. Remanesce, ao vê-la como patrimônio comum ou bem comum, um apego à concepção jusromanística de patrimônio e ainda se conserva um traço antropocêntrico, à medida que a água continua a ser vista como objeto, suscetível de apropriação, e, perpetua-se uma relação de pertença, e não de complementariedade, entre os seres humanos e a água, e, também, à medida que a motivação da mudança de visão não vai além do desiderato, louvável, porém insuficiente, de resguardar as gerações humanas seguintes, sem considerar os demais seres vivos. Neste ponto, reside uma contradição entre a compreensão da água com bem comum ou patrimônio comum com a postura mais avançada que não mais vê a natureza nem a água como coisa, mas sim, na condição de parte da natureza, como um ser vivo, sujeito de direitos e de dignidade.

Nessa seara, há necessidade de novo paradigma, de respeito ao mundo natural, pois os impactos ambientais realizados pelas ações humanas possuem um vasto reflexo na Natureza, na qualidade e na quantidade da água. A Sustentabilidade, a partir desse pensamento, tem a função de conscientizar os seres humanos que a exploração dos elementos naturais precisa de um limite drástico de respeito, para a preservação de todas as formas de vida ${ }^{17}$.

Como medida legal, têm-se o Estado, que, na sua Lei Maior, destaca a proteção a um meio ambiente saudável, essencial à vida humana e a promoção de mecanismos para a efetiva proteção. Contudo, a relevância da consciência humana e ações conscientes para preservar o meio também precisa ser destacada.

$\mathrm{Na}$ questão da água, esta precisa estar no centro da discussão, tanto pela sua imprescindibilidade para com as vidas na Terra, quanto a sua valorização, para além de uma concepção de mercado. Explicam Medeiros e Petterle, que "[...] o ser humano, ao mesmo tempo em que necessita explorar os recursos naturais, é também completamente dependente deles, o que o torna imprescindível para uma boa vida, para uma vida digna" (2005, p. 34).

Dessa forma, insiste-se que é por meio de ações humanas que o processo de evolução continuará, mas, na condição de fragilidade da vida, há necessidade de se preservar, mais e mais, o meio em que vive, pois o ser humano é o agente transformador da realidade, em uma

\footnotetext{
${ }^{16}$ Para fins deste estudo, utiliza-se o seguinte Conceito Operacional, formulado por composição, para a Categoria mencionada: "É a compreensão acerca da capacidade de resiliência entre os seres e o ambiente para se determinar de modo sincrônico e/ou diacrônico - quais são as condições favoráveis à manutenção, adaptação e perpetuação da vida equilibrada, seja humana ou não humana, a partir de uma matriz ecosófica que se manifesta pelos critérios biológicos, químicos, físicos, informacionais, éticos, territoriais, culturais, jurídicos, políticos, tecnológicos, científicos, ambientais e econômicos".

17 “A água está localizada territorialmente e precisa ser administrada localmente, partindo do reconhecimento da existência dos limites físicos materiais ao desenvolvimento. Ressalta-se assim, o valor do conhecimento e ações locais como um fator determinante das políticas eficazes. As propostas necessitam estar embasadas em diagnósticos interdisciplinares e em inovação tecnológica, mas também no resgate de sabedoria local que ensina maneiras, sedimentadas pela prática, de reproduzir a vida". (WOLKMER, 2012, p. 47)
}

Revista de Direito Brasileira | São Paulo, SP | v. 14 | n. 6 | p. 65 - 79 | maio/ago. 2016 
perspectiva de "solidariedade, de sobrevivência conjunta". (GUIMARÃES, 2013, p. 98). Nesse ponto, cabe destacar que:

Não se trata de deixar a proteção aos direitos da pessoa humana de lado, e sim uma pequena alteração no foco, já que demonstra-se tão relevante a preservação do meio para a própria perpetuação da espécie humana. A intensa degradação dos recursos naturais e, portanto, os problemas derivados da (in)sustentabilidade da vida humana na terra estão levando a humanidade a uma nova consciência redimensionando a relação entre homem e natureza. (MONT'ALVERNE; RANGEL, 2011, p. 329).

Atitudes individualistas, exclusivamente egoístas, têm conduzido a humanidade em diferentes formas de (severas) degradações ambientais que geram uma expectativa de vida e de um futuro ambiental incertos. Os riscos ${ }^{18}$ aparecem em progressão geométrica, enquanto que as respostas trazidas por um Direito puramente normativo, "fechado-em-si"19, aparecem em progressão aritmética e quase sem nenhuma eficácia.

O que se sabe é da necessidade de mudança de consciência e atitudes para melhores condições ambientais e da vida da Terra. Para tanto, chama-se a atenção para a necessidade de mudança nas concepções dos homens neste mundo individualista. Para estes autores:

[...] a questão levantada, neste momento, acerca da relevância de se estabelecer um compromisso sociojurídico de preservação do ambiente em que nos inserimos, está alicerçada na ideia de que buscamos ressaltar a necessidade do respeito recíproco, o respeito às pessoas, como seres vivos, assim como o direito à vida em geral. (MEDEIROS; PETTERLE, 2005, p. 8e 9).

Por esse motivo, a preservação da água não deve ser tratada como simples tarefa administrativa do Estado junto com os cidadãos. Ao contrário, a percepção de sua importância para a manutenção da pluralidade de ecossistemas denota novos atores, cuja presença no mundo não pode ser ignorada. A Constituição do Equador, por exemplo, inovou e trouxe os "Direitos da Natureza ${ }^{20 ", ~ r e c o n h e c e n d o-a ~ c o m o ~ " s u j e i t o ~ d e ~ d i r e i t o " . ~}$

Nessa linha de pensamento, a água: a) não deve ser tratada como "recurso" ou "patrimônio" de uma única nação, mas preocupação transversal que demanda ação dos seres humanos a partir de nossa cumplicidade vital global com tudo e todos; b) deve ser reconhecida

\footnotetext{
18 "Riscos não se esgotam, contudo, em efeitos e danos já ocorridos. Neles, exprime-se sobretudo um componente futuro. Este baseia-se em parte na extensão futura dos danos atualmente previsíveis e em parte numa perda geral de confiança ou num suposto 'amplificador do risco'. Riscos têm, portanto, fundamentalmente que ver com a antecipação, com destruições que ainda não ocorreram, mas que são iminentes, e que, justamente nesse sentido, já são reais hoje". (BECK, 2010, p. 39).

${ }^{19}$ Para Fagúndez (2000, p. 47): “[...] não se pode ter um Direito fechado em si mesmo, com seus signos, com seus princípios e métodos, sem abrir-se para as informações múltiplas e complexas que pululam fora dele. Carente de informações, a própria ciência do Direito está precisando, urgentemente, estabelecer uma conexão da normatização jurídica com a vida. [...]. Sem o resgate das leis da natureza não se conseguirá ter a visão de integridade, tão necessária para a edificação da ciência jurídica do Terceiro Milênio, alicerçada nos princípios universais tradicionalmente defendidos há milênios".

20 "A Ciência, com a Teoria de Gaia, e a Filosofia, principalmente com a Ecologia profunda, vem contribuindo para acordar a consciência do ser humano, quanto ao colapso ambiental, à ameaça de extinção da humanidade e à crise civilizatória em que vivemos e, com essa incipiente e crescente consciência ecológica, instaura-se uma mudança de paradigmas no campo do conhecimento, inclusive jurídico. Sob a perspectiva do Direito, desloca-se o eixo do ser humano, em órbita do qual gravitava e ainda gravita a idéia de direitos, para a Mãe Terra, (a natureza) como principal e prioritário titular de sujeito de direitos, paradigma ao derredor da qual surgem propostas de reestruturação de todo o edifício do saber jurídico". (MORAES, 2012, p. 12).
}

Revista de Direito Brasileira | São Paulo, SP | v. 14 | n. 6 | p. 65 - 79 | maio/ago. 2016 
como "ser próprio" para que o cuidado necessário à sua conservação favoreça o desenvolvimento da vida para todos os seres em diferentes lugares; c) demanda que as legislações a universalizem como pressuposto ao amplo desenvolvimento de povos e sua preservação biopsíquica a fim de ampliar e esclarecer a convivência entre humanos e não humanos.

\section{CONCLUSÃO}

Diante da importância da água para manutenção de todas as formas de vida, esta pesquisa destinou-se a analisar a tutela jurídica da água no Brasil, como elemento indispensável para a efetivação de outros direitos, como a vida, a saúde e a dignidade, por exemplo. Demonstrou-se a importância de uma tutela jurídica adequada em terras brasileiras, diante da diversidade natural existente no país.

O caráter de essencialidade da água sinaliza para uma proteção legal que proteja, mais e mais, o mundo natural. O Direito como fenômeno cultural e social, deve acompanhar os acontecimentos do mundo da vida, e, diante da escassez da agua, tutelar este bem jurídico fundamental na vida de cada ser.

A legislação brasileira possui como objeto os recursos hídricos do território brasileiro. A análise do aspecto legal da categoria permite concluir que a proteção da água é uma realidade, mas carece de efetivação, estando essa condiciona ao agir humano com esta finalidade. Este agir humano, com vistas na Sustentabilidade, é o que vai garantir o equilíbrio do mundo natural em comunhão com a existência humana. Como direito fundamental, a água adquire importância não somente pela possibilidade de escassez, mas sobretudo, porque é imprescindível a manutenção de tudo que vivo nesse Planeta.

O redimensionamento da categoria é importante por estes motivos. Para além de uma tutela jurídica eficiente, busca-se a conscientização de todos atores sociais na proteção de um bem tão valioso. Sociedade civil e Poder Público unem-se na jornada rumo ao futuro. Os esforços precisam ser somados. São instrumentos jurídicos e sociais que, unidos, irão proporcionar uma nova forma de tratamento à agua, na busca da efetivação de outros direitos fundamentais que dela também decorrem.

\section{REFERÊNCIAS}

ANTUNES, Paulo de Bessa. Direito ambiental. 12 ed. Rio de Janeiro: Lumen Júris, 2009.

BAUMAN, Zygmunt. Vida para consumo: a transformação das pessoas em mercadorias. Tradução de Carlos Alberto Medeiros. Rio de Janeiro: Zahar, 2008.

BECK, Ulrich. Sociedade de risco: rumo a uma outra modernidade. Tradução de Sebastião Nascimento. São Paulo: Editora 34, 2010.

CARLI, Ana Alice de. A água e seus instrumentos de efetividade. Millenium: Rio de Janeiro, 2013.

CHOQUEHUANA, David. Postulados do Bem Viver. Disponível em <http://hernehunter.blogspot.com.br/2010/02/postulados-do-viver-bem.html > Acesso e 15 set. 2015. 
FAGÚNDEZ, Paulo Roney Ávila. Direito e holismo: introdução a uma visão jurídica de integridade. São Paulo: LTr, 2000.

FIORILLO, Celso Antonio Pacheco. Curso de direito ambiental brasileiro. 6 ed. São Paulo: Saraiva, 2005.

GUDYNAS, Eduardo. Derechos de la naturaleza: ética biocéntrica y politicas ambientales. Lima: CLAES, 2014

GUIMARÃES, Bérgson Cardoso. Fundamentos ético-filosóficos para a preservação dos bens culturais. Revista Magister de Direito Ambiental e Urbanístico. Porto Alegre: Magister, 2013, p. 93-109.

HUANACUNI MAMANI, Fernando. Buen Vivir/ Vivir Bien: filosofia, políticas, estratégias y experiências rgionales andinas. Lima: CAOI, 2010.

LEITE, José Rubens Morato. Sociedade de risco e Estado. In: CANOTILHO, José Joaquim Gomes; LEITE, José Rubens Morato (orgs). Direito constitucional ambiental brasileiro. 5. ed. São Paulo: Saraiva, 2012.

MACHADO, Paulo Affonso Leme. Direito ambiental brasileiro. 17 ed. São Paulo: Malheiros, 2009.

MATTEI, Ugo. Bienes comunes: un manifiesto. Traducción de Gerardo Pisarello. Madrid: Trotta, 2013.

MEDEIROS, Fernanda Luiza Fontoura de; PETTERLE, Selma Rodrigues. Biodiversidade: uso inclusivo e sustentável do ambiente. Revista Magister de Direito Ambiental e Urbanístico. Porto Alegre: Magister, 2005, p. 5-35

MILARÉ, Edis. Direito do ambiente. 5 ed. São Paulo: Revista dos Tribunais, 2007.

MONT'ALVERNE, Tarin Cristiano Frota; RANGEL, Helano Marcio Vieira. El planeta tierra como sujeto de dignidad y de deretchos: un legado andino para la Constitución de UNASUR y para la humanidad. In: CADERMATORI, Daniela Mesquita Leutchuk;

MORAES, Germana de Oliveira; CESAR, Raquel Coelho Lenz; CADERMATORI, Sérgio Urquhart. A construção jurídica da UNASUL. Florianópolis: Editora da UFSC; Fundação Boiteux, 2011.

MORAES, Germana de Oliveira. O constitucionalismo egocêntrico nos andes: os direitos de pachamama, o bem viver e o direito à água. In: MORAES, Germana de Oliveira; GARCIA, Marcos Leite; UNNEBERG, Flávia Soares (orgs.). Para além das fronteiras: o tratamento jurídico das águas na UNASUL. Parte 1. Itajaí, (SC): Editora da UNIVALI, 2012.

MORAES, Germana de Oliveira. $\quad$ UNASUL: notas sobre a integração energética e cultural da América do Sul. Os direitos da mãe terra e a proposta do bem-viver ruma à cidadania planetária. In FREITAS, Raquel Coelho; AGUIAR, Ana Cecília Bezerra; SALES, Tainah Rodrigues 
(organizadores). UNASUL e o Novo Constitucionalismo Latino-Americano. Curitiba: CRV, 2013.

OLIVEIRA, Fábio Corrêa Souza de. Direitos da natureza e direitos dos animais: um enquadramento.

animais.

Fábio Corrêa Souza de. LOURENÇO, Daniel Braga. Heróis da natureza, inimigo dos

ORGANIZAÇÃO DAS NAÇÕES UNIDAS. Programa da Década da Água da ONU-Água sobre Advocacia e Comunicação (UNW-DPAC). Disponível

em>http://www.un.org/waterforlifedecade/pdf/human_right_to_water_and_sanitation_milestones _por.pdf $<$ Acesso em 17 de set. de 1015.

PASOLD, Cesar Luiz. Metodologia da pesquisa jurídica: teoria e prática. 12. ed. São Paulo: Conceito Editorial, 2011.

THIELBORGER, Pierre. The right(s) to water: the multi-level governance of a unique homan right. Bochum: Springer, 2014.

WOLKMER, Maria de Fátima S. O desafio ético da água como um direito humano. In: MORAES, Germana de Oliveira; GARCIA, Marcos Leite; UNNEBERG, Flávia Soares (orgs.). Para além das fronteiras: o tratamento jurídico das águas na UNASUL. Parte 1. Itajaí, (SC): Editora da UNIVALI, 2012.

ZAFFARONI, Eugenio Raul. La pachamama y el humano. Buenos Aires: Colihue, 2012. 